\title{
Determinants of anemia among pregnant women: A hospital based cross sectional study
}

\author{
P. Kalpana, A. Kavitha* \\ Department of Obstetrics and Gynecology, Malla Reddy Medical College for Women, Suraram, Hyderabad, \\ Telangana, India
}

Received: 07 June 2019

Accepted: 16 July 2019

\section{*Correspondence:}

Dr. A. Kavitha,

E-mail: kavithasukarnareddy@gmail.com

Copyright: (c) the author(s), publisher and licensee Medip Academy. This is an open-access article distributed under the terms of the Creative Commons Attribution Non-Commercial License, which permits unrestricted non-commercial use, distribution, and reproduction in any medium, provided the original work is properly cited.

\begin{abstract}
Background: The objective was to study the determinants of anemia among pregnant women. There is a negative effect on the health of the mother and as well as that of the child due to anemia in women with pregnancy. Death rate is more in women who are pregnant and having anemia. The objective of this study was to study the determinants of anemia among pregnant women.

Methods: A hospital based cross sectional study was carried out among 40 pregnant women over a period of six months. Demographic data like age, residence, occupation etc was recorded. Obstetric data like gravida, parity, previous LSCS was also recorded. The data was presented as means and student's t test was applied.

Results: The mean age was 23.43 \pm 3.4 years. Majority were young between the ages of 19-22 years. Majority belonged to urban residents i.e. $57.5 \% .20 \%$ of the subjects were found to be illiterate. Majority of the mothers were housewives i.e. $82.5 \%$. Majority were multi-gravida i.e. $60 \%$. Majority had no history of abortions in the past i.e. $75 \%$. Out of total 19 repeat pregnancies, majority i.e. $84.2 \%$ had lower segment cesarean section. Majority reported that they had normal menstrual history. The mean hemoglobin level was found out to be $7.94 \mathrm{gm} / \mathrm{dl}$. It was found that the mean hemoglobin level did not differ significantly across age, residence, education, occupation, gravidity, history of abortions, type of delivery but differed significantly by abnormal menstrual cycle.

Conclusions: Mean hemoglobin level was more in women with normal menstrual history compared to those women with abnormal menstrual history and this difference was found out to be statistically significant. Hence abnormal menses should be promptly treated, hemoglobin assessed.
\end{abstract}

Keywords: Abortions, Anemia, Determinants, Gravidity, Hemoglobin, Pregnant women

\section{INTRODUCTION}

As per World health organization (WHO) hemoglobin less than $11 \mathrm{gm} / \mathrm{dl}$ is anemia among pregnant women. It is very common in pregnant women. It can lead to spontaneous abortions, intrauterine growth retardation, sudden bleeding and many more complications associated with pregnancy. The overall physical health of the mother is affected by anemia. It can lead to low productivity.
Broadly it can affect the overall economic development of the country. There is increased morbidity and mortality associated with anemia. ${ }^{1}$ It has been estimated that nearly 0.5 billion women in the age group of 15-45 are affected by anemia all over the world. The prevalence in pregnancy has been estimated at around $38 \%$.

In some places this prevalence can cross more than half of the pregnant women. Developing countries are more 
affected as compared to the developed countries. Iron deficiency anemia is the most common in pregnant women. $^{2}$

Anemia in women with pregnancy is a global public health problem more so for the developing countries. It is also associated with unwanted outcomes for mother as well as baby. The prevalence of anemia in women with pregnancy is very common in sub-Sahara Africa amounting to the tune of $57 \%$, and $48 \%$ in South East Asia. South America showed lowest prevalence at the tune of $24.1 \% .^{3}$

Various factors can lead to occurrence of anemia in women with pregnancy. It can be caused due to deficient intake of foods rich in iron. It can also be caused by some parasitic infections. Infections of chronic nature can also cause anemia like tuberculosis. It can also be caused due to various other factors that contribute to the anemia. Or all these factors together can lead to anemia in women with pregnancy. ${ }^{4}$

There is a negative effect on the health of the mother and as well as that of the child due to anemia in women with pregnancy. Death rate is more in women who are pregnant and having anemia. The women, who are pregnant and are anemic, can have fatigue, their capacity to work gets reduced, the immune function gets impaired, they are more susceptible for the cardiac diseases and there are high chances of deaths. In developing countries, it has been shown as per the results of few studies that anemia can contribute up to $23 \%$ of deaths in women who are pregnant and anemic. ${ }^{5}$ Hence present study was carried out to study the determinants of anemia among pregnant women.

\section{METHODS}

The study was hospital based cross sectional study, done in Department of Obstetrics and Gynecology, Malla Reddy Medical College for Women, Suraram, Hyderabad, Telangana, India from November 2018 to April 2019. During the study period it was possible to study the 40 women who were pregnant and having anemia. Institutional Ethics Committee permission was taken. The nature of the study was explained to the mothers and their consent was taken before they could be included in the present study. All anemic mothers were treated as per the standard protocol. Health education and counselling was arranged for them.

\section{Inclusion criteria}

- $\quad$ Pregnant women with anemia

- Willing to participate in the present study

- $\quad$ Free from severe illness.

\section{Exclusion criteria}

- Pregnant women without anemia
- Not willing to participate in the present study

- Suffering from severe illness.

\section{Methodology}

Pregnant women with anemia were included in the present study. Demographic characteristics like age, residence, education, occupation was recorded in the pre designed, pre tested, semi structured study questionnaire developed for the present study. Clinical characteristics like gravida, number of abortions, history of previous delivery $(\mathrm{N}=19)$, menstrual history was recorded in the same study questionnaire.

Hemoglobin was tested using Sahli's hemoglobinometer.

\section{Statistical analysis}

The data was entered in the Microsoft excel worksheet and analyzed using the proportions. Mean values and standard deviation was compared between the groups and analyzed using student's t test.

\section{RESULTS}

Table 1 shows distribution of study subjects as per demographic characteristics. The mean age of the participant was 23.43 years with a standard deviation of 3.4 years.

Table 1: Distribution of study subjects as per demographic characteristics.

\begin{tabular}{|llll|}
\hline Demographic & characteristics & Number & $\%$ \\
\hline Age & $19-22$ & 18 & 45 \\
\cline { 2 - 4 } Mean age & $23-26$ & 17 & 42.5 \\
$23.43 \pm 3.4$ & 27 and above & 05 & 12.5 \\
\hline \multirow{2}{*}{ Residence } & Urban & 23 & 57.5 \\
\cline { 2 - 4 } & Rural & 17 & 42.5 \\
\hline \multirow{3}{*}{ Education } & Illiterate & 08 & 20 \\
\cline { 2 - 4 } & Up to SSC & 18 & 45 \\
\cline { 2 - 4 } & Intermediate & 11 & 27.5 \\
\cline { 2 - 4 } & Higher & 03 & 7.5 \\
\hline \multirow{2}{*}{ Occupation } & Employed & 07 & 17.5 \\
\cline { 2 - 4 } & Housewife & 33 & 82.5 \\
\hline
\end{tabular}

Majority were young between the ages of 19-22 years i.e. they constituted $45 \%$ of the total study subjects. This was followed by the age group of 23-26 years i.e. they constituted $42.5 \%$ of the total study subjects. Only five cases were aged 27 years of age and above. Majority were found out to be belonged to urban residents i.e. $57.5 \%$ compared to $42.5 \%$ who were rural residents. $20 \%$ of the subjects were found to be illiterate and the majority was studied up to SSC i.e. $45 \%$. Only three were studied beyond intermediate. Majority of the mothers were housewives i.e. $82.5 \%$ and only seven were found to be employed. 
Table 2: Distribution of study subjects as per clinical characteristics.

\begin{tabular}{|llll|}
\hline \multirow{2}{*}{ Clinical characteristics } & Number & Percentage \\
\hline \multirow{2}{*}{$\begin{array}{l}\text { Numida } \\
\text { abortions }\end{array}$} & Primi-gravida & 16 & 40 \\
\cline { 2 - 4 } & Multi-gravida & 24 & 60 \\
\cline { 2 - 4 } & Zero & 30 & 75 \\
\cline { 2 - 4 } & One & 08 & 20 \\
\hline $\begin{array}{l}\text { History of } \\
\text { previous } \\
\text { delivery } \\
\text { (N=19) }\end{array}$ & Normal & 02 & 05 \\
\cline { 2 - 4 } & LSCS & 16 & 15.8 \\
\hline $\begin{array}{l}\text { Menstrual } \\
\text { history }\end{array}$ & Abnormal & 06 & 84.2 \\
\cline { 2 - 4 } & Normal & 34 & 85 \\
\hline
\end{tabular}

Table 2 shows distribution of study subjects as per clinical characteristics. Majority were multi-gravida i.e. $60 \%$ and $40 \%$ was found to be primi. Majority had no history of abortions in the past i.e. $75 \%$ while eight had abortion once in the past and two cases reported that they had abortion twice before the present pregnancy in the past. Out of total 19 repeat pregnancies, majority i.e.
84.2\% had lower segment cesarean section while only three cases had normal vaginal delivery. Majority reported that they had normal menstrual history while only six mothers reported that they had abnormal menstrual history.

Table 3 shows distribution of study subjects as per hemoglobin levels. Out of 40 cases, $10 \%$ of the mothers had severe anemia i.e. hemoglobin was between 6-7 $\mathrm{gm} / \mathrm{dl}$. No mother was found to have hemoglobin level less than $6 \mathrm{gm} / \mathrm{dl}$. Majority i.e. 32 women i.e. $80 \%$ had hemoglobin level between 7 to $8.9 \mathrm{gm} / \mathrm{dl}$. Only four cases had hemoglobin level more than $9 \mathrm{gm} / \mathrm{dl}$. The mean hemoglobin level was found out to be $7.94 \mathrm{gm} / \mathrm{dl}$.

Table 3: Distribution of study subjects as per hemoglobin levels.

\begin{tabular}{|lll|}
\hline Hemoglobin \% & Number & Percentage \\
\hline $6-7$ & 04 & 10 \\
\hline $7-8.9$ & 32 & 80 \\
\hline 9 and above & 04 & 10 \\
\hline Total & $\mathbf{4 0}$ & $\mathbf{1 0 0}$ \\
\hline
\end{tabular}

Table 4: Association of mean hemoglobin values with demographic characteristics.

\begin{tabular}{|c|c|c|c|c|c|}
\hline \multicolumn{2}{|c|}{ Demographic characteristics } & $\mathbf{N}$ & Mean hemoglobin & T-value & P-value \\
\hline \multirow{2}{*}{ Age } & $19-22$ & 18 & $7.7 \pm 0.79$ & \multirow{2}{*}{1.5931} & \multirow{2}{*}{0.1194} \\
\hline & 22 and above & 22 & $8.1 \pm 0.79$ & & \\
\hline \multirow{2}{*}{ Residence } & Urban & 23 & $7.9 \pm 0.78$ & \multirow{2}{*}{0.0000} & \multirow{2}{*}{1.000} \\
\hline & Rural & 17 & $7.9 \pm 0.78$ & & \\
\hline \multirow{2}{*}{ Education } & Illiterate & 08 & $7.9 \pm 0.81$ & \multirow{2}{*}{0.0000} & \multirow{2}{*}{1.000} \\
\hline & Literate & 32 & $7.9 \pm 0.77$ & & \\
\hline \multirow{2}{*}{ Occupation } & Employed & 07 & $7.9 \pm 0.78$ & \multirow{2}{*}{0.0000} & \multirow{2}{*}{1.000} \\
\hline & Housewife & 33 & $7.9 \pm 0.78$ & & \\
\hline
\end{tabular}

Table 5: Association of mean hemoglobin values with clinical characteristics.

\begin{tabular}{|c|c|c|c|c|c|}
\hline \multicolumn{2}{|c|}{ Clinical characteristics } & $\mathbf{N}$ & Mean hemoglobin & T-value & P-value \\
\hline \multirow{2}{*}{ Gravida } & Primi-gravida & 16 & $7.8 \pm 0.77$ & \multirow{2}{*}{1.1977} & \multirow{2}{*}{0.2384} \\
\hline & Multi-gravida & 24 & $8.1 \pm 0.78$ & & \\
\hline \multirow{2}{*}{ Abortions } & No & 30 & $8.1 \pm 0.78$ & \multirow{2}{*}{1.3959} & \multirow{2}{*}{0.1709} \\
\hline & Yes & 10 & $7.7 \pm 0.8$ & & \\
\hline \multirow{2}{*}{ Type of delivery } & Normal & 03 & $8.1 \pm 0.49$ & \multirow{2}{*}{0.4229} & \multirow{2}{*}{0.6777} \\
\hline & LSCS & 16 & $8.3 \pm 0.78$ & & \\
\hline \multirow{2}{*}{$\begin{array}{l}\text { Menstrual } \\
\text { history }\end{array}$} & Abnormal & 06 & $7.3 \pm 0.93$ & \multirow{2}{*}{2.2545} & \multirow{2}{*}{0.0300} \\
\hline & Normal & 34 & $8.1 \pm 0.78$ & & \\
\hline
\end{tabular}

Table 4 shows association of mean hemoglobin values with demographic characteristics. The mean values with the two standard deviation; were compared between various groups like age, residence, education, and occupation. It was found that the mean hemoglobin level was more in the elderly age group compared to the younger age group, but the difference was not found out to be statistically significant. It was found that the mean hemoglobin level was same whether the mother comes from urban or rural background. It was found that the mean hemoglobin level was same whether the mother was illiterate or educated. It was found that the mean hemoglobin level was same whether the mother was occupied or working as housewife. 
Table 5 shows association of mean hemoglobin values with clinical characteristics. It was found that the mean hemoglobin level was more in the multi-gravida as compared to the primi but the difference was not found out to be statistically significant. It was found that the mean hemoglobin level more in women with no history of abortions compared to those with history of abortions the difference was not found out to be statistically significant. It was found that the mean hemoglobin level was more in those women who underwent lower segment cesarean delivery compared to those women who underwent normal delivery the difference was not found out to be statistically significant. It was found that the mean hemoglobin level was more in women with normal menstrual history compared to those women with abnormal menstrual history and this difference was found out to be statistically significant $(\mathrm{p}<0.05)$.

\section{DISCUSSION}

Kassa GM found that the pooled prevalence of anemia in women with pregnancy was $31.66 \% .^{6}$ The author stated that primi-gravida mothers and mothers from urban areas had low risk of anemia. But we found that the difference in the mean hemoglobin levels was statistically not significant between the primi-gravida and multi - gravida mothers as well as between the mothers from urban and rural background. The authors also stated that the women with malaria and gap between the two pregnancies lesser were more likely to be suffering from anemia. ${ }^{6}$

Weldekidan $\mathrm{F}$ et al carried out a case control study. They noted that the risk of anemia was 3.67 times more in women with parasitic infections compared to those without parasitic infections. They also noted that the risk of anemia was 2.49 times more in women who were not consuming the extra diet during pregnancy compared to those who are consuming the extra diet during pregnancy. They also noted that the risk of anemia was 3.58 times more in women who were consuming tea or coffee during pregnancy compared to those who are not consuming tea or coffee. They also noted that the risk of anemia was 2 times more in women who had abnormal menstrual history compared to those who are having normal menstrual history.

This finding is correlating the finding of the present study. They also noted that the risk of anemia was 2.38 times more in women who are housewives compared to those who are employed. But this finding does not match with the finding of the present study. ${ }^{7}$

Tadesse SE et al noted that the risk of anemia was 5.02 times more in women who did not consume dark green leafy vegetables compared to those who consumed. The authors noted that the risk of anemia was 2.68 times more in women who did not consume chicken compared to those who consumed. The authors noted that the risk of anemia was 2.68 times more in women who did not consume chicken compared to those who consumed.
The authors noted that the risk of anemia was 6.78 times more in women who had HIV infection compared to those who had no HIV infection. ${ }^{8}$

Mekonnen FA et al found that the prevalence of anemia was $10 \% .64 .3 \%$ were found to have mild anemia. $32 \%$ were found to have moderate anemia. $4 \%$ were found to have severe anemia. The authors noted that the anemia was statistically significantly associated with occupation and education. But we did not find any mean value difference of hemoglobin levels across education and occupation. ${ }^{9}$

Belachew $\mathrm{T}$ et al found that the prevalence of anemia was $38.2 \%$. They also observed that the mean value of the hemoglobin was $11.3 \mathrm{gm} / \mathrm{dl}$. This is very high compared to the findings of the present study where we found that the mean value of the hemoglobin was $7.94 \mathrm{gm} / \mathrm{dl}$. The risk of anemia was four times more in those with excessive bleeding during menstruation compared to those with normal menstrual cycle. This finding of the author matches with the finding of the present study. ${ }^{10}$

Desalegn $\mathrm{S}$ et al observed that the mean value of the hemoglobin was $10.9 \mathrm{gm} / \mathrm{dl}$. This is very high compared to the findings of the present study where we found that the mean value of the hemoglobin was $7.94 \mathrm{gm} / \mathrm{dl}$. The author reported that the anemia was common in women belonging to the rural areas compared to those who belonged to the urban areas. But the study did not find any such difference. The author reported that the anemia was common in illiterate women compared to those who were literate. But the study did not find any such difference. The author reported that the anemia was common in multiparity women compared to those with nulliparity or parity 1-4. But the study did not find any such difference. ${ }^{11}$

\section{CONCLUSION}

Mean hemoglobin level was very low in the present settings compared to other settings. Anemia was not found out to be associated with many factors but only with abnormal menstrual cycle's history.

Mean hemoglobin level was more in women with normal menstrual history compared to those women with abnormal menstrual history and this difference was found out to be statistically significant. Hence abnormal menses should be promptly treated, hemoglobin assessed. Present study has only 40 women as sample size. Hence all these interpretations may not be completely valid and should be interpreted with caution.

Funding: No funding sources Conflict of interest: None declared

Ethical approval: The study was approved by the Institutional Ethics Committee 


\section{REFERENCES}

1. World Health Organization. Global nutrition targets 2025: anaemia policy brief (WHO/NMH/NHD/14.4) Geneva: World Health Organization; 2014. Available from:https://www.who.int/nutrition/publications/glob altargets2025_policybrief_anaemia/en/ Accessed on: 11-01-2019

2. Kaźmierczak W, Fiegler P, Adamowicz R, Muszer M, Kamiński K. Prevention of iron deficiency anemia--influence on the course of pregnancy, delivery and the infant's status. Wiad Lek. 2004;57(1):144-7.

3. Worldwide prevalence of anaemia. 1993. Available at: http://apps.who.int/iris/bitstream/10665/43894/ 1/9789241596657_eng.pdf. Accessed on 22 February 2019.

4. Ononge S, Campbell O, Mirembe F. Hemoglobin status and predictors of anaemia among pregnant women in Mpigi. Uganda. BMC Res Notes. 2014;7:712.

5. Black RE, Victora CG, Walker SP, Bhutta ZA, Christian P, Onis M. Maternal and child nutrition study group. Maternal and child under nutrition and overweight in low-income and middle-income countries. Lancet. 2013;382(9890):427-51.

6. Kassa GM, Muche AA, Berhe AK, Fekadu GA. Prevalence and determinants of anemia among pregnant women in Ethiopia; a systematic review and meta analysis. BMC Hematol. 2017;17:17.
7. Weldekidan F, Kote M, Girma M, Boti N, Gultie T. Determinants of anemia among pregnant women attending antenatal clinic in public health facilities at Durame Town: unmatched case control study. Anemia. 2018;2018:8938307.

8. Tadesse SE, Seid O, Mariam YG, Fekadu A, Wasihun Y, Endris K. Determinants of anemia among pregnant mothers attending antenatal care in Dessie town health facilities, northern central Ethiopia, unmatched case control study. PLoS One. 2017;12(3):173.

9. Mekonnen FA, Ambaw YA, Neri GT. Socio economic determinants of anemia in pregnancy in north Shoa Zone, Ethiopia. PLoS One. 2018;13(8):e0202734.

10. Belachew T, Legesse Y. Risk factors for anemia among pregnant women attending antenatal clinic at Jimma University Hospital, southwest Ethiopia. Ethiop Med J. 2006;44(3):211-20.

11. Desalegn S. Prevalence of anemia in pregnancy in Jima town, southwestern Ethiopia. Ethiop Med J. 1993;31(4):251-8.

Cite this article as: Kalpana $\mathrm{P}$, Kavitha $\mathrm{A}$.

Determinants of anemia among pregnant women: A hospital based cross sectional study. Int J Reprod Contracept Obstet Gynecol 2019;8:3609-13. 